\title{
Awareness about Risk Factors of Colorectal Cancer among Employees at Minia University
}

\author{
Huda T.Selim ${ }^{(1)}$ Yossria E. Hossein ${ }^{(2)}$, Ebtesam E. Hassan, ${ }^{(3)}$ Manar D. Mohammed ${ }^{(4)}$
}

1. BSc. in Nursing, Faculty of Nursing, Minia University

2. Professor of Community Health Nursing, Faculty of Nursing - Minia University

3. Assistant. professor of Public Health and Preventive Medicine, Faculty of Medicine - Minia University

4. Lecturer of Community Health Nursing, Faculty of Nursing - Minia University

\begin{abstract}
Background: Colorectal cancer (CRC) is cancer that begins in the colon or rectum, depending on where it is located, these cancers may also be called colon cancer or rectal cancer, and it is the third most common tumor in Egypt in males after urinary bladder and lymphohematopoietic malignancies and ranks fifth in females following bladder cancers. Aim of the study: The present study aimed to assess awareness about risk factors of colorectal cancer among employees at Minia University. Design: A cross-sectional design was used for this study. Setting: This study was conducted at five faculties in Minia University (Faculty of Medicine, Faculty of Early Childhood Education, Faculty of Tourism and Hotels, Faculty of Science, and Faculty of Nursing) randomly selected. Sample: The study was conducted on 365 employees from the selected faculties to participate in this study over six months from July 2020 to December 2020. Tool of data Collection Data were collected through a structured questionnaire, consisted of two parts: Part I: personal data of employees. Part II: Bowel / colorectal cancer awareness assessment. Results: More than half $(56.7 \%)$ of the study participants had poor CRC awareness. Education, family history, occupation, and residence were the significant factors related to participants' awareness (p-value 0.00, 0.006, 0.001, 0.001 respectively). Conclusion: This study concluded that the majority of participants had inadequate awareness about colorectal cancer risk factors. There is a highly statistically significant difference as regards the level of awareness of participants and their level of education, family history of $\mathrm{CRC}$, occupation, and residence. Recommendations: Encourage health practitioners to disseminate information to the general public on safe lifestyles and cancer prevention and conducting further researches to investigate barriers and misconceptions about CRC screening programs.
\end{abstract}

Keywords: Awareness, Risk Factors, Colorectal Cancer.

\section{Introduction}

Cancer is the second major cause of death following heart diseases; it is a class of diseases characterized by uncontrolled cell growth and begins with a loss of tumor suppressor ability in the cell cycle due to genetic mutations (Szollosi et al., 2020). Such growths also invade the surrounding tissue and may metastasize to distant locations (Bashir et al., 2020).

Colorectal Cancer (CRC) is a type of gastrointestinal malignancy originating from either the colon or the rectum; they are often grouped together because of the many biologically and clinically common features (Van et al., 2019). The exact causes of the vast majority of CRCs remain unknown; it could be based on numerous genetic and environmental changes. Most CRCs are sporadic but can arise from inherited cancer syndromes, inflammatory conditions, and modifiable lifestyle factors (Sierra et al., 2016).

Colorectal Cancer (CRC) can be diagnosed by a combination of measures include taking a health history, physical examination, complete blood count, blood chemistry tests, stool tests like a guaiac fecal occult blood test or fecal immunochemical test, double-contrast barium enema, sigmoidoscopy, colonoscopy, biopsy, digital rectal examination, cell and tissue studies, CT scan, ultrasound, MRI, chest X-ray, and PET scan (Anusha et al., 2016).

Over eighty six percent $(86 \%)$ of those diagnosed with CRC under the age of 50 are asymptomatic, and the disease is being diagnosed at later stages, in symptomatic patients, the disease may generate changes in bowel motility (e.g., diarrhea or constipation), occult or evident colorectal bleeding, as well as abdominal discomfort, cramping,

$P$ a g e $\mid \mathbf{4 0}$ unexplainable weight loss, weakness, and fatigue, especially in patients with advanced-stage CRC (Mattiuzzi et al., 2019).

There are several risk factors for CRC; the individual risk of $\mathrm{CRC}$ is essentially dependent on non-modifiable dispositional factors such as age, sex, and family history (Ma et al., 2018). Modifiable risk factors of $\mathrm{CRC}$ are related to lifestyles such as lack of physical activity, obesity (overweight), unhealthy food (excessive red meat, processed meat, fatty diet, low fruits and vegetables, and low intake of calcium, fiber, milk, whole-grain, and vitamin D), excessive smoking (tobacco smoking), and excessive alcohol consumption (Surya et al., 2020).

Colorectal cancer (CRC) affects men and women of all racial and ethnic groups and is most often found in those aged fifty (50) years or older! its incidence in males is significantly higher than that in females (Pradhan et al., 2020). Patients with a personal CRC history or adenomatous polyps of the colon are at risk for the future development of colon cancer, also diabetes mellitus together with obesity, radiation, chronic or repeated episodic inflammatory insults to the intestinal mucosa have a clear mechanistic role in the development of CRC (Powell et al., 2020).

Colorectal Cancer (CRC) is a preventable disease, and it is estimated that about $75 \%$ of CRC cases could be avoided with a healthy lifestyle. Most cancer prevention strategies are primary or secondary, the primary prevention goal is to prevent cancer from starting by reducing individual risk, and it focuses on lifestyle changes, health education, and risk factors related to chemoprevention (lee, 2018).

Secondary prevention enables slow-growing lesions to be diagnosed at early stages, focusing on reducing further

Huda T., et al 
complications, disabilities, or suffering and it includes early diagnosis, screening methods. Tertiary prevention aims to prevent recurrence or progression of the disease and focuses on efforts to prevent cancer formation in patients that have previously been treated (i.e., cancer survivors) (Tran et al., 2019).

Treatment of CRC involves three main options, surgery, chemotherapy, and radiation therapy, either alone or as adjuvant treatment, it depends on the disease stage. Earlier stages of disease (stages I through III) are referred to as localized colorectal cancers and are generally treated with surgery (with or without chemotherapy), but stage IV cancer is called advanced colorectal cancer and is generally treated with palliative chemotherapy (Berghella et al., 2019).

Postoperative follow-up included clinical examination, serum carcinoembryonic antigen (CEA) levels, and abdominal ultrasound every three (3) months during the first two (2) years and then every six (6) months for two (2) years. A thoraco-abdominopelvic CT scan is performed every 6 months for the first 2 years and then every year for three (3) years, while colonoscopy was done after one (1) year, and if it was normal, it was repeated after three (3) years (Farhat et al., 2019).

Awareness plays a vital role in the early diagnosis and improving the survival rate of CRC patients, it has been directly related to the screening program participation. National policies and programs should be focused on prevention by raising awareness, reducing exposure to cancer risk factors, providing information and support to adopt healthy lifestyles (Saranrittichai et al., 2020), in order to raise interest in awareness and prevention of colorectal cancer, president Bill Clinton designated March as national colorectal cancer awareness month that started in the year 2000 (Pantel et al., 2020).

Community Health Nurse (CHN) plays an important role in preventive healthcare measures, especially those who work in primary care offices and community clinics. Through education, CHN can improve awareness of younger people and those with a lower level of education who had poor awareness of lifestyle risk factors for CRC, especially since this group stands to benefit most from risk reduction (Abuadas et al., 2019).

In primary prevention, community health nurses (CHNs) play a key role in identifying patients at CRC risk, providing new information about risk factors and the rising incidence in younger patients to help prevent and identify $\mathrm{CRC}$ at earlier, more treatable stages. CHNs play an important role in CRC secondary prevention through education, and thus increasing screening rates in asymptomatic high-risk populations in the community, initiate prompt treatment, arrest progression, and prevent associated disability (Al-Sharif et al., 2018), also they need to implement tertiary prevention at the community level by establishing working partnerships with community leaders and stakeholder organizations to prevent CRC complications, they help to find out the patient and do home visits to provide care and health education on CRC management, palliative care and healthy lifestyle (Saranrittichai et al, 2020).

\section{Significance of the study}

Colorectal Cancer (CRC) is a leading cause of mortality and morbidity throughout the world and its incidence is steadily rising in developing nations, thus representing a major public health problem (Rawla et al.,
2019). Globally, it is the third most common malignant neoplasm, with nearly 1.8 million new cases in 2018; its global burden is expected to increase by $60 \%$ to more than 2.2 million new cases and 1.1 million deaths by 2030 (Araghi et al., 2019).

The relative frequency of CRC in Egypt is about 9$12 \%$ with high male predominance $3: 1$. According to the Egypt National Cancer Registry, age-specific incidence rates of CRC per 100,000 were 6.3 for males and 4.3 for females in 2009. According to Minia Cancer Registry in 2011, the crude incidence rate of CRC was about 3.4 per 100,000 populations in the Minia governorate (Mahfouz et al, 2014). The incidence rate in Egypt is $5.1 \%$ in males and $4.7 \%$ in females (El-Din et al., 2020).

\section{Aim of the study}

The current study aimed to assess awareness about risk factors of colorectal cancer among employees at Minia University.

\section{Research questions}

1. What is the level of awareness about risk factors of colorectal cancer among employees at Minia University?

2. Is there a relationship between socio-demographic characteristics and the level of awareness about risk factors of colorectal cancer among employees at Minia University?

\section{Subject and Methods \\ Research Design:}

Across-sectional descriptive design was used to achieve the aim of the present study.

\section{Setting:}

This study was conducted at Minia University. Minia University has consisted of twenty (20) faculties, five (5) faculties (Faculty of Medicine - Faculty of Early Childhood Education - Faculty of Tourism and Hotels-Faculty of Science -Faculty of Nursing) were randomly selected to participate in this study.

\section{Subjects:}

According to the National Cancer Registry, the prevalence of colorectal cancer in Egypt $(12 \%)$, the total number of the employees at Minia University (2276) in 2020, as stated by the central personnel administration of Minia University, The sample size was estimated to fulfill the aim of the study, with a $95 \%$ level of confidence and a study power of $80 \%$. By using the Epi-info computer software program the required sample size was (365) were selected by using convenient sampling as follows:

\begin{tabular}{|l|l|l|l|l|l|l|}
\hline Faculty & $\begin{array}{l}\text { Medi } \\
\text { cine }\end{array}$ & $\begin{array}{l}\text { Touris } \\
\mathbf{m} \text { and } \\
\text { Hotels }\end{array}$ & $\begin{array}{l}\text { Early } \\
\text { Child } \\
\text { hood } \\
\text { Educa } \\
\text { tion }\end{array}$ & $\begin{array}{l}\text { Scie } \\
\text { nce }\end{array}$ & $\begin{array}{l}\text { Nu } \\
\text { rsin } \\
\text { g }\end{array}$ & \\
\hline $\begin{array}{l}\text { Total Number } \\
\text { faculty's } \\
\text { Employees }\end{array}$ & 173 & 87 & 67 & 140 & 104 & 571 \\
\hline Ratio (\%) & 30.2 & 15.3 & 11.7 & 24.5 & 18.3 & 100 \\
\hline $\begin{array}{l}\text { Number of } \\
\text { sample }\end{array}$ & 110 & 56 & 43 & 89 & 67 & $\mathbf{3 6 5}$ \\
\hline
\end{tabular}

Inclusion Criteria: 
○ The white-collar employees and blue-collar employees within the selected faculties of Minia University.

\section{Exclusion Criteria:}

- Employees who took time off work for over 3 months.

\section{Tool for Data Collection:}

Data were collected through a structured questionnaire that was adopted from another instrument developed by Cancer Research UK, University College London, and Oxford University in 2007-2008 and updated in 2011(Power et al., 2011), and some modifications were done by the investigator. It consisted of two parts:

\section{I-First part: Interviewing questionnaire:}

It covered the data related to the participants (name, age, gender, residence, education, occupation, marital status, and CRC family history).

\section{II-Second part: Bowel / colorectal cancer awareness assessment:}

The questionnaire has consisted of thirty (30) items and addressed general awareness about CRC \{fourteen (14) items\}, risk factors \{twelve (12) items\}, treatment, and follow-up \{four (4) items\}.

Scoring System: - according to (Simon, 2010) (Su, 2013), (Mhaidat, 2018).

A scoring system for colorectal cancer awareness was used where each correct answer \{(yes) or (agree or strongly agree in Likert scale questionnaire) $\}$ were given one point and incorrect answer $\{(\mathrm{No})$ or (strongly disagree, disagree, neither in Likert scale questionnaire) $\}$ were given a zero score.

Regarding negative questions, \{(yes) or (agree or strongly agree in Likert scale questionnaire) $\}$ were given zero scores as a false answer, but $\{(\mathrm{No})$ or (strongly disagree, disagree, neither in Likert scale questionnaire)\} were given one point as a correct answer.

Each question will be rated (zero) for the wrong answer, and (1) for the right answer, the knowledge score will be calculated by summing the scores for all questions (30 questions) thus the overall score ranged from (0-30).

\section{The level of Awareness was classified as:}

- Up to $17(<60 \%)$ considered poor,

- from 18-24 (>60-80\%) considered fair,

- And from 25-30 (>80-100\%) considered good.

Validity:

The tool was submitted to a jury of five panels of experts in the community health field to test the content validity of the tools (four experts at Minia University, Faculty of nursing, and one expert at Minia University, faculty of medicine, community health, and preventive medicine department).

The tools were examined for content coverage, the sequence of items, clarity, relevance, applicability, wording, length, format, and overall appearance. Some modifications were done.

\section{Reliability:}

$P$ a g e 142
The reliability of the tool was performed to confirm the consistency of the tool. The internal consistency was measured to identify the extent to which the items of the tool measured what it was intended to measure. The internal consistency of the tool was assessed with Cronbach's alpha coefficient. Cronbach's $\alpha$ coefficient of 0.00 indicates no reliability, and a coefficient of 1.00 indicates perfect reliability. However, a reliability coefficient of 0.9 is acceptable.

\section{Ethical consideration:}

The preliminary written approval was approved by the research ethics committee of the faculty of nursing, Minia University. Oral informed consent was obtained from participants after explaining the nature and benefits of the study. Each assessment sheet was coded and participants' names will not appear on the sheets for the purpose of privacy and confidentiality. Participants were assured that they could withdraw at any time from the current study. Measures were taken to protect participants' ethical rights.

\section{Pilot study:-}

A pilot study was performed on 37 workers $(10 \%)$ before beginning to collect data to assess the effectiveness and applicability of the questionnaire, as well as to determine the best time to collect data. They were included in the study.

\section{Administrative design}

Before starting data collection, five formal letters were issued from faculty of nursing, Minia University, to the deans of faculty of medicine, faculty of early childhood education, faculty of tourism and hotels, faculty of science, and faculty of nursing to gain the administrative approval.

\section{The Preparatory Phase:}

A review of the related literature which covered various aspects of the research problem was done, using different books, journals, and websites, to get knowledge of colorectal cancer including definition, causes, risk factors, diagnosis, treatment, and prevention.

\section{Field Work:}

Meeting with employees in small groups with suitable recommended distance in-between persons as a protective measure, and explaining the objectives of the study to gain their cooperation.

Oral consent was taken; the purpose and the nature of the study were explained by the investigator through direct personal communications before starting to participate in the study.

Employees were interviewed per day from 9 AM to 1 PM in two days each week for 6 months from July 2020 to December 2020 within a range of 25 to 30 minutes for every employee with an average of eight employees per day. The white-collar employees filled the questionnaire by themselves, but the blue-collar employees' questionnaires were filled in by the investigator after explanation for the sake of the accuracy of the questionnaire. Steps to protect the moral rights of participants were taken.

\section{Statistical Design:}

Data were analyzed using version 20 of the Statistical Software Package for Social Sciences (SPSS), Numerical data were expressed as mean and SD. Quantitative data were 
expressed as frequency and percentage. For quantitative data, a comparison between two variables was done using a t-test, and a comparison between more than two variables used the ANOVA test. Relations between different numerical variables were tested using the Pearson correlation.

\section{Limitation of the study:}

- Relative lack of employees' cooperation.

- Some employees' unwilling to participate in the study.
- As coronavirus (COVID-19) was declared a pandemic by the world health organization (WHO), Minia University has taken suitable measures to control it as social distances, reduce the number of employees on work, and new safeguards to minimize the risk of infection, so it was difficult to go there and take data, losing some time and thus impact my research.

\section{Results}

Table 1: Distribution of the studied employees as regarding sociodemographic characters $(\mathbf{n}=\mathbf{3 6 5})$.

\begin{tabular}{|c|c|c|}
\hline Data & Number $(\mathbf{N})$ & Percentage (\%) \\
\hline \multicolumn{3}{|l|}{ Age (years) : } \\
\hline $\begin{array}{l}\text { Range } \\
\qquad(\text { Mean } \pm \text { SD) }\end{array}$ & $\begin{array}{l}23-59 \\
39.5 \pm 11.413\end{array}$ & - \\
\hline \multicolumn{3}{|l|}{ Sex : } \\
\hline Male & 164 & 44.9 \\
\hline Female & 201 & 55.1 \\
\hline \multicolumn{3}{|l|}{ Residence : } \\
\hline Urban & 242 & 66.3 \\
\hline Rural & 123 & 33.7 \\
\hline \multicolumn{3}{|l|}{ Marital status : } \\
\hline Single & 36 & 9.9 \\
\hline Married & 310 & 84.9 \\
\hline Widow & 10 & 2.7 \\
\hline Divorced & 8 & 2.2 \\
\hline \multicolumn{3}{|l|}{ Education level： } \\
\hline Illiterate & 91 & 24.9 \\
\hline Read and write & 51 & 14.0 \\
\hline Secondary & 105 & 28.8 \\
\hline University and higher & 118 & 32.3 \\
\hline \multicolumn{3}{|l|}{ Occupation : } \\
\hline White-collar employees & 222 & 60.8 \\
\hline Blue-collar employees & 148 & 39.2 \\
\hline \multicolumn{3}{|c|}{ Family History of Colorectal Cancer : } \\
\hline Yes & 12 & 3.3 \\
\hline No & 353 & 96.7 \\
\hline
\end{tabular}

Table 1 summarizes the socio-demographic characteristics of the Studied Participants. The age of participants ranged between 23 and 59 years (mean $39.5 \pm 11.413$ years), females constituted $55.1 \%$, while $66.3 \%$ of the studied employees lived in urban areas and the vast majority of them (84.9\%) were married. Regarding educational level, 32.3 were highly educated; also $60.8 \%$ of them were white-collar employees and $39.2 \%$ are blue-collar employees. Positive family history of CRC was found among $3.3 \%$ of the studied participants.

\section{Table 2: Frequency distribution of questions directed to employees regarding general awareness about $\mathrm{CRC}(\mathrm{n}=365)$.}

\begin{tabular}{|c|c|c|c|c|}
\hline \multirow{2}{*}{ Information } & \multicolumn{2}{|l|}{ Yes } & \multicolumn{2}{|l|}{ No } \\
\hline & N. & $\%$ & $\mathbf{N}$ & $\%$ \\
\hline Having an idea about CRC. & 273 & 74.8 & 92 & 25.2 \\
\hline CRC is a leading cause of cancer death. & 198 & 54.2 & 167 & 45.8 \\
\hline Both men and women are at the same risk for CRC. & 343 & 94.0 & 22 & 6.0 \\
\hline There are known causes of CRC. & 161 & 44.1 & 204 & 55.9 \\
\hline CRC is a preventable disease. & 149 & 40.8 & 216 & 59.2 \\
\hline Bleeding from the back passage is a sign of bowel cancer. & 252 & 69.0 & 113 & 31.0 \\
\hline Persistent pain in the abdomen (tummy) is a sign of bowel cancer. & 222 & 60.8 & 143 & 39.2 \\
\hline Change in bowel habits (diarrhea, constipation, or both) over a period of weeks is a sign of bowel cancer. & 204 & 55.9 & 161 & 44.1 \\
\hline Feeling that bowel does not completely empty after using the lavatory is a sign of bowel cancer. & 34 & 9.3 & 331 & 90.7 \\
\hline Blood in stools is a sign of bowel cancer. & 252 & 69.0 & 113 & 31.0 \\
\hline Contacting doctor if you had a CRC symptom. & 270 & 74.0 & 95 & 26.0 \\
\hline CRC screening tests. & 126 & 34.5 & 239 & 65.5 \\
\hline CRC screening begins after 50 years old. & 131 & 35.9 & 234 & 64.1 \\
\hline Colorectal screening is not necessary if there are no symptoms. & 218 & 59.7 & 147 & 40.3 \\
\hline
\end{tabular}

Table 2: shows that about two thirds (74.8\%) of the participants have heard about CRC, more than half of them agreed that it is a leading cause of death from cancer, but the majority of the study participants $(94.0 \%)$ thought that women and men are at the same level of CRC risk. Regarding CRC causes, (44.1\%) have believed that CRC causes were known, (59.2\%) of studied employees considered that colorectal cancer can be prevented.

The most commonly known CRC signs were bleeding from the back passage and blood in the stool (69 \% for each) whereas not completely emptied bowel after defecation was the least common $(9.3 \%) .60 .8 \%$ of the studied employees thought that persistent pain in the abdomen is a symptom, but (44.1\%) of the studied employees thought that a change in bowel habits is not a sign of CRC. about two-thirds of the studied employees had the intention to visit a doctor if they had any of the signs and symptoms, but more than 
half of them (65.5\%) didn't know about screening tests, the age for CRC screening (64.1\%), and 59.7 \% of them believed that no necessary for CRC screening if no sign or symptom would be present.

Table 3: Frequency distribution of the studied participants regarding CRC risk factors' awareness (n=365).

\begin{tabular}{|c|c|c|c|c|}
\hline \multirow[t]{2}{*}{ Risk factor } & \multicolumn{2}{|c|}{ Strongly agree, Agree } & \multicolumn{2}{|c|}{$\begin{array}{l}\text { Neither, } \\
\text { Disagree, Strongly disagree }\end{array}$} \\
\hline & N. & $\%$ & N. & $\%$ \\
\hline Being over 70 years old. & 182 & 49.9 & 183 & 50.1 \\
\hline Having a close relative with bowel cancer. & 227 & 62.2 & 138 & 37.8 \\
\hline Being physically inactive. & 195 & 53.4 & 170 & 46.6 \\
\hline Obesity as a risk factor for CRC. & 201 & 55.1 & 164 & 44.9 \\
\hline A history of excessive smoking. & 268 & 73.4 & 97 & 26.6 \\
\hline Excessive alcohol consumption. & 226 & 61.9 & 139 & 38.1 \\
\hline Eating red meat (more than 500 gram/week) or processed meat. & 156 & 42.7 & 209 & 57.3 \\
\hline Low fruits and low raw vegetables. & 175 & 47.9 & 190 & 52.1 \\
\hline Low fiber diet. & 205 & 56.2 & 160 & 43.8 \\
\hline Having a bowel disease (e.g. ulcerative colitis, Crohn's disease). & 242 & 66.3 & 123 & 33.7 \\
\hline Suffering from diabetes. & 146 & 40.0 & 219 & 60.0 \\
\hline Repeated exposure to x-ray. & 173 & 47.4 & 192 & 52.6 \\
\hline
\end{tabular}

Table 3 describes the individual items constituting the knowledge grid to measure participants' awareness about CRC risk factors; the most frequently recognized CRC risk factor was having a history of excessive smoking $(\mathrm{n}=268 ; 73.4 \%)$, and diabetes was the least recognized $(\mathrm{n}=146 ; 40.0 \%)$. About half of the participants gave a correct answer for CRC age-related risk. Among 365 participants, about $(66.3 \%),(62.2 \%)$ and $(61.9 \%)$ participants believed that having a bowel disease, having a close relative with bowel cancer, and excessive alcohol consumption were related to CRC risk respectively.

The studied employees who have recognized that a low fiber diet was a risk factor for CRC disease only made up a ratio of $56.2 \%$, just over half of the participants have supposed that obesity (55.1\%) and low physical activity (53.4) were related to CRC risk. On the other hand, less than half of the participants agreed that a diet low in fruits and vegetables (47.9\%), x-ray (47.4 \%), and excessive red and processed meat intake (42.7\%) were associated with CRC occurrence.

Table 4: Frequency distribution of the studied participants regarding CRC Treatment and follow up (n=365).

\begin{tabular}{|c|c|c|c|c|}
\hline \multirow{2}{*}{ CRC treatment and follow up } & \multicolumn{2}{|l|}{ Yes } & \multicolumn{2}{|l|}{ NO } \\
\hline & N. & $\%$ & N. & $\%$ \\
\hline Treatment includes surgery, chemotherapy or radiation therapy, or a combination of the above modalities. & 261 & 71.5 & 104 & 28.5 \\
\hline Compliance with treatment is very necessary to achieve a cure. & 276 & 75.6 & 75.6 & 24.4 \\
\hline Good nutrition is necessary during treatment. & 291 & 79.7 & 74 & 20.3 \\
\hline Follow-up following completion of treatment is essential to detect recurrence. & 307 & 84.1 & 58 & 15.9 \\
\hline
\end{tabular}

Table 4 shows participants' awareness about treatment and follow-up; about two-thirds of them correctly answered questions 1, 2, and 3 about CRC treatment choices, compliance, and the importance of good nutrition during treatment. The vast majority of the participants (84.1) had a good awareness of the importance of follow-up.

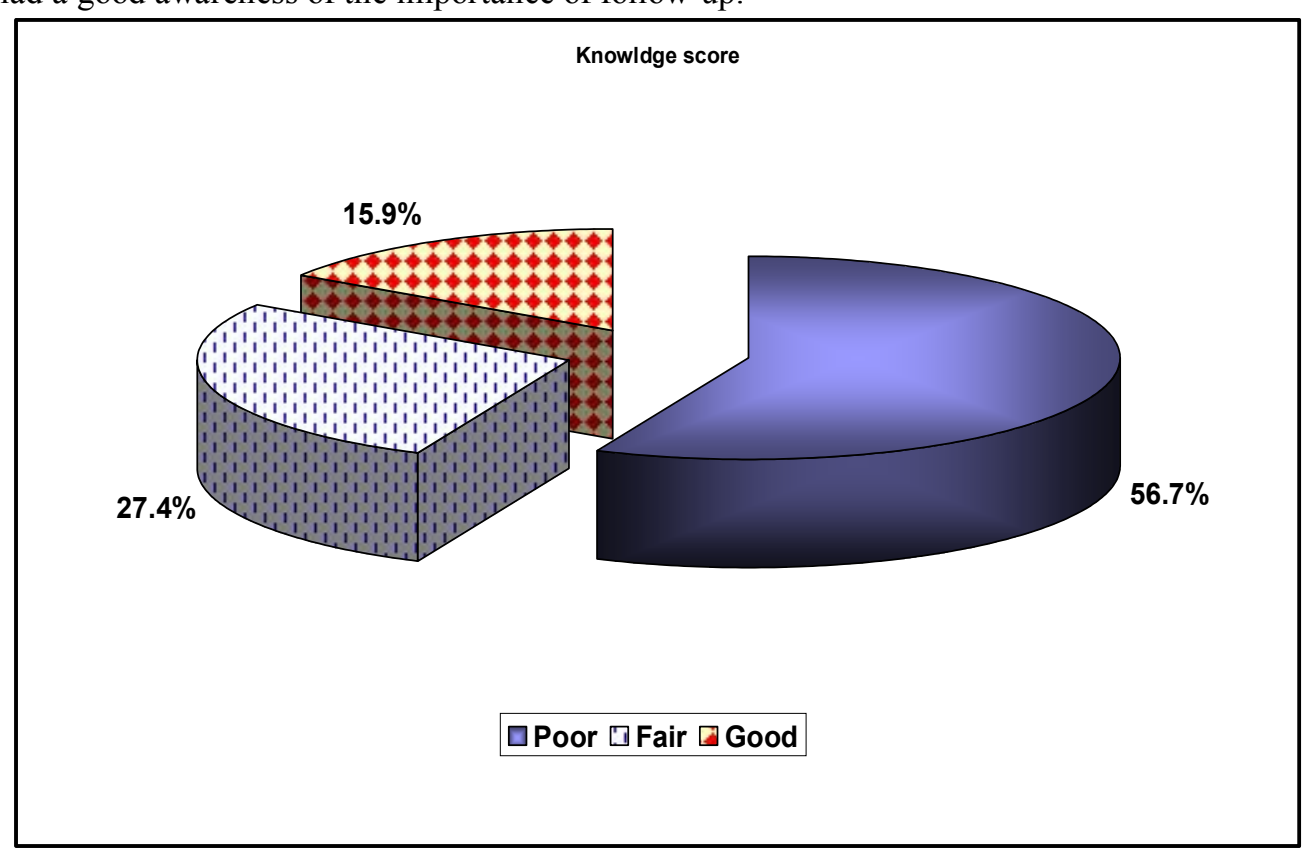

Fig.1: Total knowledge score of participants about colorectal cancer $(n=365)$.

Fig. 1 depicts the participant's level of knowledge about CRC; shows that over half of the participants (56.7 \%) had poor awareness about CRC cancer, while about quarter of them (27.4\%) were knowledgeable, only $15.9 \%$ of the studied employees had good awareness level about CRC. 
Table 5: Relation between the studied participants' socio-demographic data and knowledge score on colorectal cancer $(\mathbf{n}=365)$

\begin{tabular}{|c|c|c|c|c|c|c|}
\hline \multirow{3}{*}{ Data } & \multicolumn{4}{|c|}{ Knowledge } & \multirow{3}{*}{$\mathrm{X}^{2}$} & \multirow{3}{*}{ p-valuc } \\
\hline & Poor & \multirow{2}{*}{$\begin{array}{l}\text { Fair } \\
\text { N. }(\%)\end{array}$} & Good & Total & & \\
\hline & N. $(\%)$ & & N. $(\%)$ & N.(\%) & & \\
\hline \multicolumn{7}{|l|}{ Sex } \\
\hline Male & $97(46.9)$ & $39(39.0)$ & $28(48.3)$ & $164(44.9)$ & \multirow[b]{2}{*}{1.995} & \multirow{2}{*}{0.36} \\
\hline Female & $110(53.1)$ & $61(61.0)$ & $30(51.7)$ & $201(55.1)$ & & \\
\hline \multicolumn{7}{|l|}{ Residence } \\
\hline Urban & $100(48.3)$ & $91(91)$ & $51(87.9)$ & $242(66.3)$ & \multirow{2}{*}{69.4} & \multirow{2}{*}{$11^{*}$} \\
\hline Rural & $107(51.7)$ & $9(9)$ & $7(12.1 \%)$ & $123(33.7)$ & & \\
\hline \multicolumn{7}{|l|}{ Marital status } \\
\hline Single & $23(11.1)$ & $7(7.0)$ & $6(10.5)$ & $36(9.9)$ & \multirow{4}{*}{1.650} & \multirow{4}{*}{0.94} \\
\hline Married & $174(84.1)$ & $88(88.0)$ & $48(84.2)$ & $310(85.2)$ & & \\
\hline Widow & $5(2.4)$ & $3(3.0)$ & $2(3.5)$ & $10(2.7)$ & & \\
\hline Divorced & $5(2.4)$ & $2(2.0)$ & $1(1.8)$ & $8(2.2)$ & & \\
\hline \multicolumn{7}{|l|}{ Occupation } \\
\hline White-collar & $102(49.3)$ & $74(74.0)$ & $46(79.3)$ & $222(60.8)$ & \multirow{2}{*}{7.19} & \multirow{2}{*}{$.001 *$} \\
\hline Blue-collar & $105(50.7)$ & $26(26.0)$ & $12(20.7)$ & $143(39.2)$ & & \\
\hline \multicolumn{7}{|c|}{ Family History of CRC } \\
\hline Yes & $1(0.5)$ & $1(1)$ & $10(17.2)$ & $12(3.3)$ & \multirow{2}{*}{42.2} & \multirow{2}{*}{$.006 *$} \\
\hline No & $206(99.5)$ & $99(99)$ & $48(82.7)$ & $353(96.7)$ & & \\
\hline
\end{tabular}

Table 5 shows the relationship between demographic characteristics of participants and overall knowledge of CRC; from the descriptive analysis, female participants and married participants had a higher score of knowledge regarding CRC. However, the differences were not statistically significant. It should be noted that a difference was only statistically significant at the level .05 with the residence as participants from urban areas scored significantly better $(\mathrm{P}=0.001)$ than those from rural areas. White-collar employees had better knowledge scores than blue-collar employees in this study with significant differences $(\mathrm{P}=0.00)$, and those with $\mathrm{CRC}$ family history were more knowledgeable than those without a family history $(\mathrm{p}=0.006)$.

Table 6: The Relationship between the age of studied employees and their Knowledge Score (n=365).

\begin{tabular}{|l|l|l|l|l|}
\hline \multirow{2}{*}{} & \multirow{2}{*}{$\mathbf{N}$} & Age & \multirow{2}{*}{ (Range) } & p-value \\
\cline { 3 - 3 } & & Mean \pm SD & & \multirow{2}{*}{$23-59$} \\
Poor & 207 & $39.29 \pm 11.167$ & 0.76 \\
\hline Fair & 100 & $40.19 \pm 11.48$ & & \\
\hline Good & 58 & $39.05 \pm 12.27$ & \\
\hline
\end{tabular}

Table 6 shows that participants with fair knowledge score had a higher age mean than others (40.19 \pm 11.489 years), good with a mean age of $39.05 \pm 12.272$ years, and poor with a mean age of $39.29 \pm 11.167$. P-value was not significant.

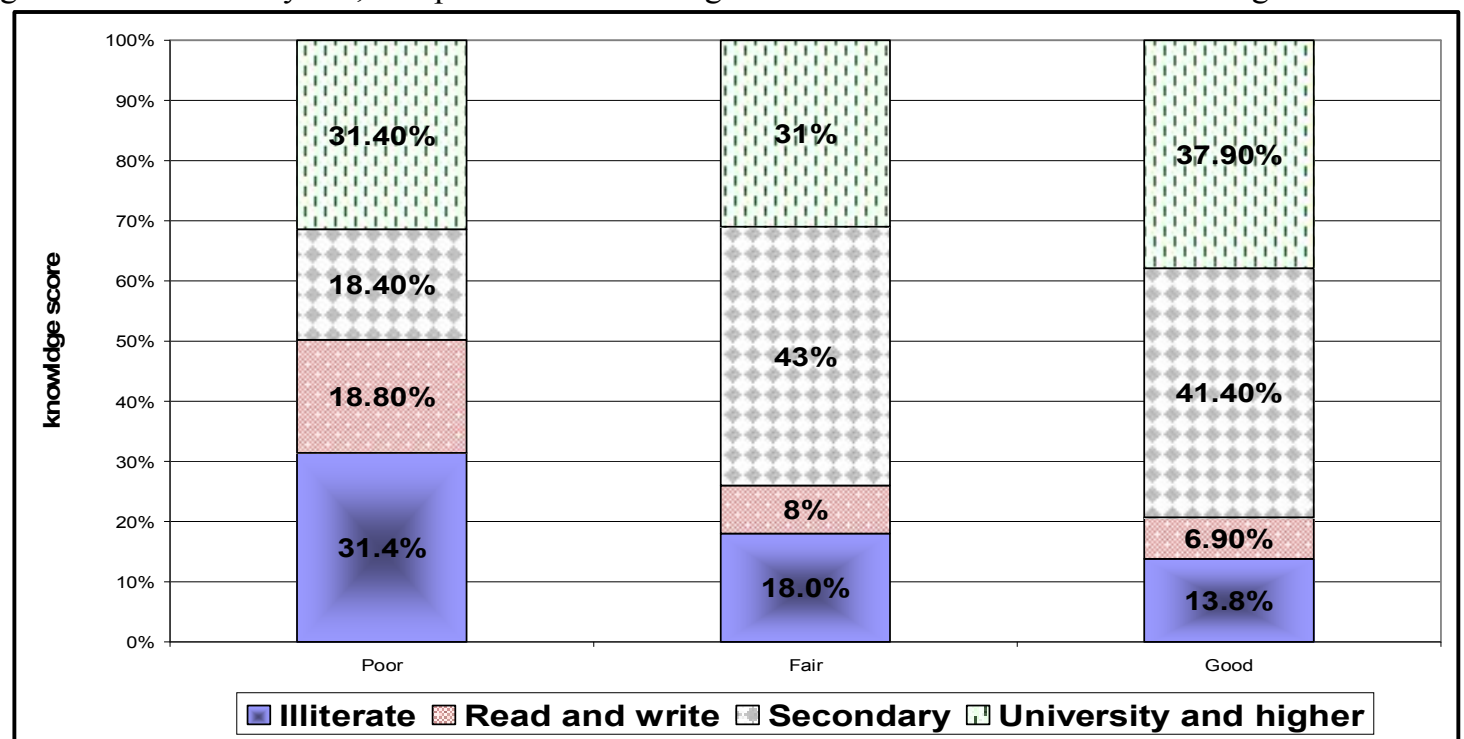

Fig.2: Relation between the studied participants' level of education and knowledge score on colorectal cancer $(\mathrm{n}=365$ )

Fig.2 indicates the significant association between better knowledge score level and higher educational level $(\mathrm{P}=0.00)$. 


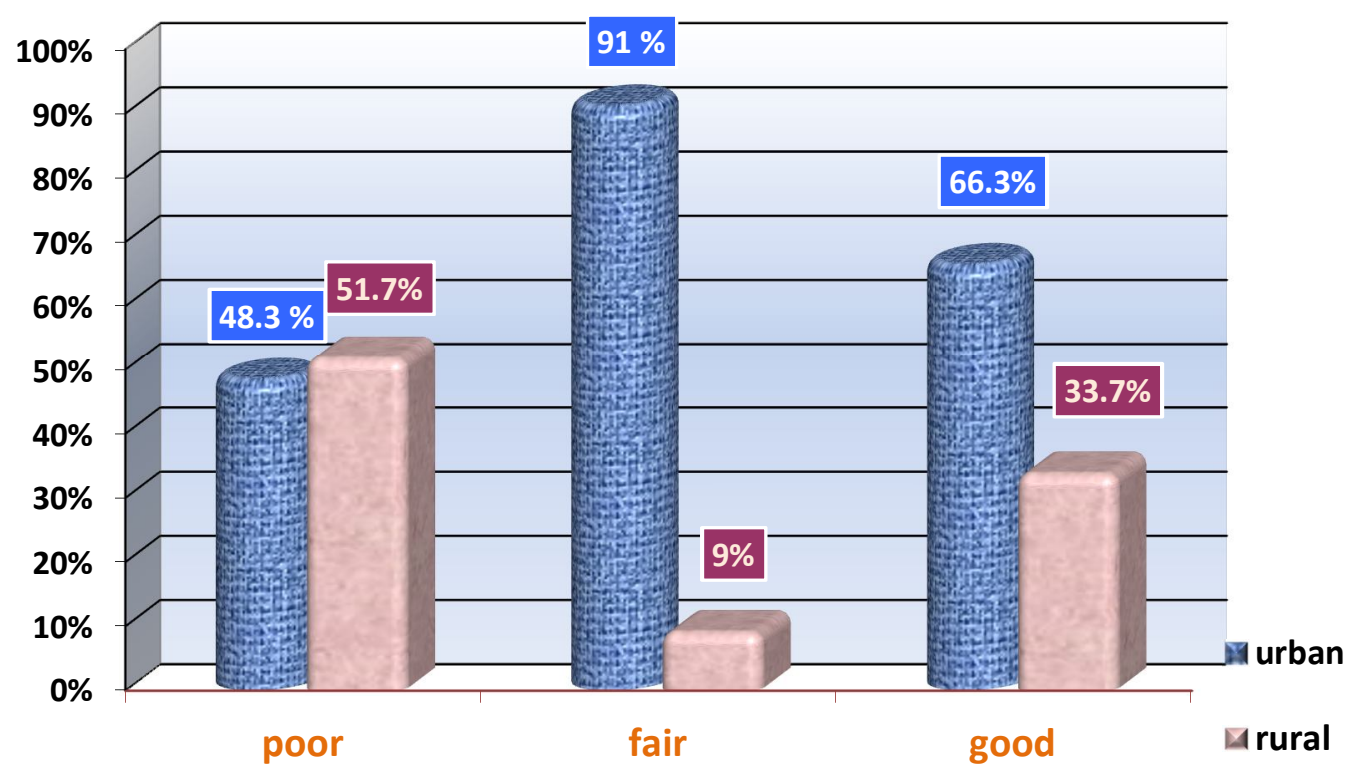

\section{fig.3 Relation between the studied participants' risidence and knowledge score on colorectal cancer}

Fig.3 shows the significant association between the residence in urban areas and better knowledge score level and ( $\mathrm{P}=0.001)$.

\section{Discussion}

The aim of the current study is to assess awareness about risk factors of $\mathrm{CRC}$ among employees at Minia University.

Regards to the demographic characters of the study participants, the present study showed that more than half of the participants were females and the majority of them were married. The study participants were within the age range between 23-59 years (mean age of $39.5 \pm 11.413$ years) and about two-thirds of them were from urban areas. Regarding the educational level and occupation, closer to a third of the participants were highly educated and more than half of them were white-collar employees.

Regarding the general colorectal cancer awareness, this study revealed that the majority of the study participants had an idea about CRC; this result was in agreement with (Gede et al., 2018) who studied "Colorectal cancer and screening awareness and sources of information in the Hungarian population", and they found that the majority of the participants had heard about CRC.

This study revealed that the majority of the participants incorrectly answered that men and women are at the same risk for CRC. This study result disagrees with the study conducted by (Al-Maghrabi, 2016) who studied "Assessment of the knowledge and awareness of colorectal cancer among the general population of Makkah" and he found that more than one-third of participants were aware that men are more likely to suffer from colorectal cancer.

Regarding the current study results, only less than half of the study participants supposed that CRC can be prevented, this result was compatible with (Al-Thafar et al., 2017) who studied "Knowledge Attitude and Practice of Colorectal Cancer among School Teachers in Al-Ahsa Saudi Arabia" and they found that only less than one-quarter of the participants believed that CRC is preventable. In our point of view, our participants' poor answers may be due to a lack of community awareness programs and insufficient emphasis on the magnitude problem of colorectal cancer in Egypt.
This study indicated that about two-thirds of the participants thought that bleeding from the back passage and blood in stools are signs of colorectal cancer, more than half of the study participants agreed that persistent pain in the abdomen and changes in the bowel habits over a period of weeks may be signs of CRC.

These current results were similar to many studies such as the study of (Sindhu et al., 2019) who studied" Awareness of Colorectal Cancer among the Urban Population in the Klang Valley", (Tfaily et al., 2019) who studied "Awareness of colorectal cancer and attitudes towards its screening guidelines in Lebanon", (Mhaidat et al., 2018) who studied "Knowledge and awareness of colorectal cancer early warning signs and risk factors among university students in Jordan", and they found that more than half of their studies' participants considered that bleeding from the back passage, blood in stools, persistent pain in the abdomen, and changes in the bowel habits are signs of CRC.

A small group of this study's participants knew that incomplete emptying of the bowel after defecation is a sign of CRC. This result is in agreement with (Al-Dahshan et al., 2020) who studied "Colorectal cancer awareness and its predictors among adults aged 50-74 years attending primary healthcare in the State of Qatar", and (Al-Thafar et al., 2017) who found that only less than third of all participants knew that incomplete emptying of bowel after defecation is a sign of CRC.

Regarding seeking help and screening, the results of this present study indicated that around two-thirds of the participants tended to visit a doctor if they had any CRC symptoms, only less than one-third of them knew about CRC screening tests, only about one-third of them knew about the age recommended for CRC screening (fifty years old or older) and believed that there is no necessary for CRC screening if there are no signs or symptoms.

This result was confirmed by (Schliemann et al., 2020) who studied" Change in public awareness of colorectal cancer symptoms following the Be Cancer Alert Campaign in the multi-ethnic population of Malaysia" and they found the 
majority of their study participants intended to seek medical help if they had CRC symptoms and with (Imran et al., 2016) who studied "Knowledge and awareness of colorectal cancer among undergraduate students at King Abdulaziz University, Jeddah, Saudi Arabia: a survey-based study " and revealed that less than one-third of the study population identified the CRC screening tests.

This current study's results were greatly similar to those of (Juon et al., 2018) who studied "Predictors of colorectal cancer knowledge and screening among Asian Americans Aged 50-75 years old" and stated that more than half of participants supposed no need for CRC screening if there are no symptoms. I think that the participants didn't care about CRC screening due to their poor awareness of the symptoms and because there were no free CRC screening initiatives.

Regarding CRC risk factors, excessive smoking was the most frequently recognized risk factor by around twothirds of this study participants, this result comes in accordance with (Tfaily et al., 2019), and (Galal et al., 2016) who studied "Colon cancer among older Saudis: Awareness of risk factors and early signs and perceived barriers to screening", both reported that smoking was the most frequently agreed CRC risk factor by more than half of the participants.

More than a half of this study participants supposed excessive alcohol consumption as a CRC risk factor, this finding was in the same line with the studies of (Al-Thafar et al., 2017), and Al-(Dahshan et al., 2020), they all found that about two-thirds of their study respondents agreed that excessive alcohol consumption increases the risk of CRC. Unsurprisingly, these results may be related to Islamic religious faith and Arabic culture, where drinking alcohol is forbidden and cigarette smoking is discouraged, and also due to the fact that smoking and excessive drinking are harmful according to much-related literature.

More than a half of this study participants believed that having a bowel disease or having a close relative with bowel cancer increases CRC risk, these results come with (Tfaily et al., 2019) who studied "Awareness of colorectal cancer and attitudes towards its screening guidelines in Lebanon" as they reported that more than half of participants knew that bowel diseases or having a family member with CRC increase CRC risk.

Slightly more than half of the study participants agreed that a low fiber diet, obesity, and physical inactivity increase CRC risk. The studies related to (Al-Thafar et al., 2017), and (Tfaily et al., 2019) supported pre-stated results as they found that more than half of their studies' respondents agreed that a low fiber diet and obesity are considered CRC risk factors, also these current results come in line with (Rocke, 2019) who studied "Colorectal Cancer Knowledge and Awareness Among University Students in a Caribbean Territory" and he reported that more than half of the participants knew that being physically inactive elevates the risk of colorectal cancer. The reason for this may be due to the traditional culture that links food to every sad or happy occasion, and also due to bad lifestyles such as unhealthy food and inactivity.

This study revealed that less than half of the participants considered being aged, low fruits, vegetable diet, and repeated exposure to x-ray as CRC risk factors. These results were congruent with the studies conducted by (Tfaily et al., 2019) and (Al-Thafar et al., 2017) reported that less than half of the participants agreed to be over 70 years old, with low fruits and vegetable diet increase CRC risk. (Saeed et al., 2018) in their study about "Knowledge and Awareness of Colorectal Cancer among General Public of Kuwait" supported this study's results as they found that less than half the participants agreed that repeated exposure to $\mathrm{x}$-ray is a CRC risk factor if it is repeated.

Suffering from diabetes was the least frequent CRC risk factor as it was recognized by only slightly more than one-third of the current study participants. This result was supported by (Al-Thafar et al., 2017), and Saeed et al., (2018) all of them reported that the least risk factor agreed by the participants was diabetes.

As regarding awareness about CRC treatment and follow up, higher than two thirds to three-quarters of this current study participants had a high level of awareness towards CRC treatment and follow up, these results are congruent with (Zheng et al., 2016) who studied" Factors associated with intentions to adhere to colorectal cancer screening follow-up exams" and they found that around threequarters of respondents agreed to the importance of treatment and follow up.

Overall, the current study findings revealed a general lack of knowledge and understanding about CRC risk factors. The study showed that more than half of the participants had poor awareness, more than one-quarter of them had fair awareness, and only less than one-sixth of the participants had good knowledge. This may have resulted since there are not many awareness programs and educational material focusing on colorectal cancer and its risk factors in Egypt.

These findings were in agreement with the studies done by (Al-Sharbatti et al., 2017) who studied "Predictors of Colorectal Cancer Knowledge among Adults in the United Arab Emirates" which reported that more than half of participants had poor knowledge scores for CRC. On the contrary, the current study results are inconsistent with (Rocke, 2019) as he reported that satisfactory/good knowledge was seen among about two-thirds of his study population, this may be due to the different population and site, as he targeted the university students who had a higher level of education, and the study took place in Caribbean Territory that may be supported by American health education programs about CRC.

Regarding the relation between participants' awareness about colorectal cancer and their demographic characteristics, the current study revealed that there is a positive statistically significant relationship between CRC awareness and the participants' residence, occupation, educational level, and family CRC history. Urban, whitecollar employees, those participants with a CRC family history or who had a higher level of education were more significantly knowledgeable than those from rural areas, bluecollar employees, those without a family history, and with lower education.

On the other hand, there was an insignificant statistical relation between CRC and age, gender, and marital status, awareness was found to increase with older, female, and married participants. These results were in agreement with the study done by (Sindhu et al., 2019), (Galal et al., 2016), who stated that there is a statistically significant relationship between participants' awareness of CRC and their education level, occupation, the previous history of $\mathrm{CRC}$, and residence as they found that urban Malaysians, with higher levels of education and higher occupation, are generally more aware of 
the risk factors for CRC, also showed no significant difference in the awareness of CRC based on age, gender, marital status.

These current findings were in agreement with those who reported that Participants with higher educational levels and those having relatives with CRC had a significantly higher awareness of the disease; however, the relation with gender was not significant. In the same line, this study results were congruent with (Nasaif, 2018) who studied" Knowledge of colorectal cancer symptoms and risk factors in the Kingdom of Bahrain: A cross-sectional study "and revealed that there was an association between family history of CRC linked to a better level of knowledge. Additionally, Females had better knowledge than males although the disease affects men more than women.

\section{Conclusion} concluded that:

Based on the finding of the present study, it can be

Overall knowledge was low. Poor awareness about $\mathrm{CRC}$ and its risk factors was found among more than half of the study participants, only less than one-sixth of the participants showed good knowledge regarding CRC risk factors. Regarding socio-demographic characteristics of the study participants and their relation with CRC risk factors awareness, Poor levels of awareness were significantly associated with lower levels of education (P-value $=0.00)$, blue-collar employees $(\mathrm{P}$-value $=0.00)$, having no relatives with $\mathrm{CRC}(\mathrm{P}$-value $=0.02)$, and rural residents $(\mathrm{P}$-value $=0.04)$.

\section{Recommendation:-}

In view of the results of this study, we suggested the following recommendations:-

O Health education programs to increase awareness of colorectal cancer and its risk factors.

E Encourage health professionals to disseminate healthy lifestyle and cancer prevention knowledge effectively and appropriately to the general population.

O Conducting further researches to investigate barriers and misconceptions around $\mathrm{CRC}$ screening programs.

O Mass media (Television, radio, and press) should be used to disseminate CRC awareness.

- Leaflet materials could be distributed in different governorates and regions in Egypt to help increase CRC awareness.

\section{References}

(1) Abuadas, F. H., \& Abuadas, M. H. (2019). An Interventional Study to Improve Colorectal Cancer Screening Knowledge and Health Perceptions among Jordanians' Average Risk Population. The Open Nursing Journal, 13(1).

(2) Al-Dahshan, A., Chehab, M., Bala, M., Omer, M., almohamed, O., Al-Kubaisi, N., \& Selim, N. (2020). Colorectal cancer awareness and its predictors among adults aged 50-74 years attending primary healthcare in the State of Qatar: a cross-sectional study. BMJ Open, 10(7), e035651.

(3) Al-Maghrabi, A. A. (2016). Assessment of the knowledge and awareness of colorectal cancer among general population of Makkah: a survey based study. Screening, 4(4), 168-175.

(4) Al-Sharbatti, S., Muttappallymyalil, J., Sreedharan, J., \& Almosawy, Y. (2017). Predictors of colorectal cancer knowledge among adults in the United Arab Emirates.
Asian Pacific journal of cancer prevention: APJCP, 18(9), 2355.

(5) Al-Sharif, M. N., Fayi, K. A., Alobaidi, A. A., \& Alshamrani, B. A. (2018). Awareness of colorectal cancer among public in Asir region. Journal of family medicine and primary care, $7(1), 87$.

(6) Al-Thafar, A. K., Al-Naim, A. F., Albges, D. S., Boqursain, S. K., Aldhafar, A. S., Ghreiz, S. M., \& Ibrahim, S. (2017). Knowledge attitude and practice of colorectal cancer among school teachers in Al-Ahsa Saudi Arabia. Asian Pacific journal of cancer prevention: APJCP, 18(10), 2771.

(7) Anusha, P., \& Nagarathnam, M. (2016). Assessment of Knowledge on Colorectal Cancer among Caregivers at Tertiary Care Hospital, Andhra Pradesh.

(8) Araghi, M., Soerjomataram, I., Jenkins, M., Brierley, J., Morris, E., Bray, F., \& Arnold, M. (2019). Global trends in colorectal cancer mortality: projections to the year 2035. International journal of cancer, 144(12), 2992-3000.

(9) Bader El Din, N. G., Ibrahim, M. K., El $\square$ Shenawy, R., Salum, G. M., Farouk, S., Zayed, N., .. \& El Awady, M. (2020). Micrornas expression profiling in Egyptian colorectal cancer patients. IUBMB Life, 72(2), 275-284.

(10) Bashir, F., Akhtar, J., Anjum, N., Alam, S., \& Khan, A. A. (2020). Concept of Sartān (Cancer) and Anti-Cancerous Drugs in Unani System of Medicine. International Journal of Current Science and Multidisciplinary Research, No159.

(11) Berghella, A. M., Aureli, A., Canossi, A., Del Beato, T., Colanardi, A., \& Pellegrini, P. (2019). Redox, immune and genetic biomarker system for personalized treatments in colorectal cancer. World Journal of Gastrointestinal Oncology, 11(2), 117.

(12) Farhat, W., Azzaza, M., Mizouni, A., Ammar, H., ben Ltaifa, M., Lagha, S., ... \& Ali, A. B. (2019). Factors predicting recurrence after curative resection for rectal cancer: a 16-year study. World journal of surgical oncology, 17(1), 173.

(13) Galal, Y. S., Amin, T. T., Alarfaj, A. K., Almulhim, A. A., Aljughaiman, A. A., Almulla, A. K., \& Abdelhai, R. A. (2016). Colon cancer among older Saudis: Awareness of risk factors and early signs, and perceived barriers to screening. Asian Pacific Journal of Cancer Prevention, 17(4), 1837-1846.

(14) Gede, N., Kiss, D. R., \& Kiss, I. (2018). Colorectal cancer and screening awareness and sources of information in the Hungarian population. BMC family practice, 19(1), 106.

(15) Imran, M., Sayedalamin, Z., Alsulami, S. S., Atta, M., \& Baig, M. (2016). Knowledge and awareness of colorectal cancer among undergraduate students at King Abdulaziz University, Jeddah, Saudi Arabia: a survey-based study. Asian Pacific Journal of Cancer Prevention, 17(5), 24792483.

(16) Juon, H. S., Guo, J., Kim, J., \& Lee, S. (2018). Predictors of colorectal cancer knowledge and screening among Asian Americans Aged 50-75 years old. Journal of racial and ethnic health disparities, 5(3), 545-552.

(17) Lee, S. Y. (2018). Koreans' awareness and preventive behaviors regarding colorectal cancer screening. Asian Pacific Journal of Cancer Prevention: APJCP, 19(9), 2657.

(18) Ma, H., Brosens, L. A., Offerhaus, G. J. A., Giardiello, F. M., de Leng, W. W., \& Montgomery, E. A. (2018). Pathology and genetics of hereditary colorectal cancer. Pathology, 50(1), 49-59.

(19) Mahfouz, E. M., Sadek, R. R., Abdel-Latief, W. M., Mosallem, F. A., \& Hassan, E. E. (2014). The role of dietary and lifestyle factors in the development of colorectal cancer: case control study in Minia, Egypt. Cent Eur J Public Health, 22(4), 215-22. 
(20) Mattiuzzi, C., Sanchis-Gomar, F., \& Lippi, G. (2019). Concise update on colorectal cancer epidemiology. Ann Transl Med, 7, 609.

(21) Mhaidat, N. M., Al-husein, B. A., Alzoubi, K. H., Hatamleh, D. I., Khader, Y., Matalqah, S., \& Albsoul, A. (2018). Knowledge and awareness of colorectal cancer early warning signs and risk factors among university students in Jordan. Journal of Cancer Education, 33(2), 448-456.

(22) Nasaif, H. A., \& Al Qallaf, S. M. (2018). Knowledge of colorectal cancer symptoms and risk factors in the Kingdom of Bahrain: A cross-sectional study. Asian Pacific journal of cancer prevention: APJCP, 19(8), 2299.

(23) Pantel, H. J., Kleiman, D. A., Kuhnen, A. H., Marcello, P. W., Stafford, C., \& Ricciardi, R. (2020). Has National Colorectal Cancer Awareness Month increased endoscopy screening rates and public interest in colorectal cancer?. Surgical Endoscopy, 1-8.

(24) Powell, W., Frerichs, L., Townsley, R., Mayorga, M., Richmond, J., Corbie-Smith, G., ... \& Hassmiller Lich, K. (2020). The potential impact of the Affordable Care Act and Medicaid expansion on reducing colorectal cancer screening disparities in African American males. Plos one, 15(1), e0226942.

(25) Pradhan, R., Yin, H., Oriana, H. Y., \& Azoulay, L. (2020). The Use of Long-Acting Insulin Analogs and the Risk of Colorectal Cancer Among Patients with Type 2 Diabetes: A Population-Based Cohort Study. Drug Safety, 43(2), 103-110.

(26) Rawla, P., Sunkara, T., \& Barsouk, A. (2019). Epidemiology of colorectal cancer: Incidence, mortality, survival, and risk factors. Przegla $\square$ d Gastroenterologiczny, 14(2), 89.

(27) Rocke, K. D. (2019). Colorectal cancer knowledge and awareness among university students in a Caribbean Territory: a cross-sectional study. Journal of Cancer Education, 1-8.

(28) Saeed, R. S., Bakir, Y. Y., Alkhalifah, K. H., \& Ali, L. M. (2018). Knowledge and Awareness of Colorectal Cancer among General Public of Kuwait. Asian Pacific Journal of Cancer Prevention: APJCP, 19(9), 2455.

(29) Saranrittichai, K., Ussavapark, W., Thamrongwarangkoon, A., Heangsorn, T., Daoruang, S., \& Teeranut, A. (2020). Community-based approaches to cancer prevention in rural Thailand Based on experiences of accredited health professionals. Asian Pacific Journal of Cancer Prevention: APJCP, 21(1), 7.

(30) Schliemann, D., Paramasivam, D., Dahlui, M., Cardwell, C. R., Somasundaram, S., Tamin, N. S. B. I., ... \& Donnelly, M. (2020). Change in public awareness of colorectal cancer symptoms following the Be Cancer Alert Campaign in the multi-ethnic population of Malaysia. BMC cancer, 20(1), 1-12.

(31) Sierra, M. S., \& Forman, D. (2016). Etiology of colorectal cancer (C18-20) in Central and South America. Cancer in Central and South America. Lyon: International Agency for Research on Cancer.

(32) Simon, A. E., Waller, J., Robb, K., \& Wardle, J. (2010). Patient delay in presentation of possible cancer symptoms: the contribution of knowledge and attitudes in a population sample from the United Kingdom. Cancer Epidemiology and Prevention Biomarkers, 19(9), 2272-2277.

(33) Sindhu, C. K., Nijar, A. K., Leong, P. Y., Li, Z. Q., Hong, C. Y., Malar, L., ... \& Kwa, S. K. (2019). Awareness of Colorectal Cancer among the Urban Population in the Klang Valley. Malaysian Family Physician: the Official Journal of the Academy of Family Physicians of Malaysia, 14(3), 18.

(34) Su, T. T., Goh, J. Y., Tan, J., Muhaimah, A. R., Pigeneswaren, Y., Khairun, N. S., ... \& Majid, H. A. (2013). Level of colorectal cancer awareness: a cross sectional exploratory study among multi-ethnic rural population in Malaysia. BMC cancer, 13(1), 376.

(35) Surya, R. (2020). Mechanistic Hypotheses on Colorectal Cancer and Red Meat Intake: A Review. E\&ES, 426(1), 012176.

(36) Szollosi, D. E., Kinney, S. R., Amin, A. R., \& Chumbow, N. (2020). Cancer Immunotherapy. In Pharmacology of Immunotherapeutic Drugs (pp. 321-355). Springer, Cham.

(37) Tfaily, M. A., Naamani, D., Kassir, A., Sleiman, S., Ouattara, M., Moacdieh, M. P., \& Jaffa, M. A. (2019). Awareness of colorectal cancer and attitudes towards its screening guidelines in Lebanon. Annals of global health, $85(1)$.

(38) Tran, P. N., \& Zell, J. A. (2019). Gastrointestinal Cancer Prevention: Diet, Lifestyle, and Therapeutic Prevention. In Textbook of Gastrointestinal Oncology (pp. 509-532). Springer, Cham.

(39) Van Veen, M. R., Mols, F., Bours, M. J., Weijenberg, M. P., Kampman, E., \& Beijer, S. (2019). Adherence to the World Cancer Research Fund/American Institute for Cancer Research recommendations for cancer prevention is associated with better health-related quality of life among long- term colorectal cancer survivors: results of the profiles registry. Supportive Care incancer,1-10.

(40) Zheng, Y. F., Saito, T., Takahashi, M., Ishibashi, T., \& Kai, I. (2016). Factors associated with intentions to adhere to colorectal cancer screening follow-up exams. BMC Public Health, (61), 272. 